\title{
UNCERTAINTY IN LANDSLIDES VOLUME ESTIMATION USING DEMS GENERATED BY AIRBORNE LASER SCANNER AND PHOTOGRAMMETRY DATA
}

\author{
C. Parente ${ }^{1}$, M. Pepe ${ }^{1, *}$ \\ ${ }^{1}$ Department of Sciences and Technologies, University of Naples "Parthenope", Italy \\ (claudio.parente; massimiliano.pepe)@uniparthenope.it
}

Commission ICWG III/IVa

KEY WORDS: ALS, Digital Elevation Model, DoD, Volume estimation, landslide, airborne sensor.

\begin{abstract}
:
The purpose of this paper is to identify an approach able to estimate the uncertainty related to the measure of terrain volume generated after a landslide. The survey of the area interested of landslide can be performed by Photogrammetry \& Remote Sensing (PaRS) techniques. Indeed, depending on the method and technology used for the survey, a different level of accuracy is achievable. The estimate of the quantity of the terrain implicated in the landslide influences the type of geological and geotechnical approach, the civil engineering project on the area and of consequence, the costs to sustain for a community. According to the experiences and recommendations reported in the ASPRS guidelines, an example of the approach used to estimate volumetric accuracy concerning one of the most important landslide in Europe is shown in this paper. In this case study, the dataset is constituted by a Digital Elevation Model (DEM) obtained by photogrammetric (stereo-images) method (pre-landslide) and another by Airborne Laser Scanner (after-landslide). By the comparisons of Airborne Laser Scanner (ALS) and photogrammetry DEMs obtained from successive surveys, it has been possible to produce maps of differences and of consequence, to calculate the volume of the terrain (eroded or accumulated). In order to calculate the uncertainty of volume, a procedure that takes in account even the different accuracy achievable in the vegetation area is explained and discussed.
\end{abstract}

\section{INTRODUCTION}

Volumetric change analysis plays an important role in the observation of some phenomena, such as the estimation of earthflow quantity generated after a landslide. A common method used to analyse the landslides phenomena is the DEMs (Digital Elevation Models) difference (DoD). This technique consists in comparing more DEMs acquired over the time (James, et al, 2012; William, 2012). For this reason, DoD map allows to interpret the evolution of geomorphological processes and to quantitatively assess morphological changes due to erosion and/or accumulation on landslide (Bossi et al, 2016). In order to describe the topography of Area Of Interest (AOI), the survey can be carried out by several geomatics techniques: digital photogrammetric aerial images (Hapke, 2005), Airborne Laser Scanner (ALS) (Jaboyedoff et al, 2012; Garnero \& Godone, 2013), space-borne Synthetic Aperture Radar (SAR) interferometry (Colesanti \& Wasowski, 2006; Osmanoğlu et al, 2016), Terrestrial Laser Scanner (Bitelli et al, 2004) and satellite images (Seker et al, 2004; Nichol et al., 2006). In this paper, the attention is focused on the DEMs generated by stereo-images obtained by airborne sensor and ALS technology.

The monitoring of landslide processes by stereoscopic aerial photography is applied and known for a long time (Fookes et al, 1991; Lee \& Min, 2001; Karsli, et al., 2004). The advantage of using photogrammetry method is to identify in easy mode the area interested by landslide activity. The accuracy of photogrammetric measurements mainly depends on the flying height. Therefore, performing the aerial survey to low height, it was possible to achieve centimetre accuracy for points on the ground (Brückl, et al, 2006). Passini \& Jacobsen (2008) have showed by a test with different aerial digital sensors (Vexcel Imaging UltraCamD, UltraCamX, Z/I Imaging DMC digital frame and 3D-CCD-line scanner camera Leica ADS40) that the accuracy achieved in terms of RMSE (Root Mean Square Error), using a Ground Sample Distance (GSD) of about $5 \mathrm{~cm}$, has been of few centimetres. However, this method does not allow to obtain terrain information if the area of study is cover by high and dense vegetation. Of course, the accuracy in vegetation area decreases considerably. In this way, the Italian Technical Requirements for the Production of DTM suggest a tolerance value in vegetation area a quarter of the threes height.

As concerning the ALS survey, over the last few years this technique is increasingly widespread thanks to its ability to produce, in short times, dense point clouds. In the case of the landslide surveys, using ALS data it is possible to realize landslide morphology maps and to obtain spatial information even in areas that are partly or completely covered by dense vegetation (Razak et al, 2011). Indeed, using ALS sensor and carried out a suitable post-processing data, it is possible to create accurate and precise High Resolution Digital Elevation models (HRDEM) in raster grids or Triangulated Irregular Networks, so-called TINs (Maglione et al, 2014), which are $2.5 \mathrm{D}$ representations of the topography or in true $3 \mathrm{D}$ point clouds with a high density of information (Jaboyedoff et al. 2012). Vosselman and Maas (2001) have showed that the accuracy onto planimetry are often much larger than onto the height and the accuracy ranges from 10 to $20 \mathrm{~cm}$. Csanyi and Toth (2007) in order to analyse both planimetric and height

\footnotetext{
* massimiliano.pepe@uniparthenope.it
} 
accuracies of laser point clouds, have designed special ground targets: the comparison between the coordinates of the targets obtained by ALS sensor and by GPS (Global Positioning System) has showed a planimetric accuracy of 5$10 \mathrm{~cm}$ and height accuracy of $2-3 \mathrm{~cm}$. Vosselman (2008; 2012) by specific case studies and suitable methods, has showed that the horizontal accuracy can be contained in 5 $\mathrm{cm}$. However, the accuracy values achieved in these papers have been obtained in optimal condition and open environment. Other studies, which consider the vegetation, show a higher error. Reutebuch et al, 2003 in the survey on forested lands in western Washington have obtained the mean and standard deviation of vertical errors between the Digital Terrain Models (DTM) and 347 ground checkpoints of $0.22 \mathrm{~m}$ and $0.24 \mathrm{~m}$, respectively (RMSE $=0.32 \mathrm{~m}$ ). This order of error is similar but lower than that obtained by Kraus and Pfeifer (1998) for a wooded area in Austria (RMSE $=0.57 \mathrm{~m}$ ). The study conducted over the Utikuma Uplands boreal wetland located north of Utikuma Lake (Canada) by Hopkinson et al., 2005 has showed that the range accuracy varies from $0.10 \mathrm{~m}$ to $0.84 \mathrm{~m}$. Leitold et al, 2015 have compared Digital Terrain Models (DTM) derived from airborne lidar data from a mountainous region of the Atlantic Forest in Brazil to 35 ground control points measured with survey Global Navigation Satellite Systems (GNSS) receivers. The height difference achieved has been of $0.19 \pm 0.97 \mathrm{~m}$. In the issue about the level of accuracy achievable by ALS sensor, ASPRS Positional Accuracy Standards for Digital Geospatial Data guideline (ASPRS, 2014) suggest some formula and threshold values. Indeed, from the Table B.9 contains in the section "Vertical Accuracy and Recommended Lidar Point Density for Digital Elevation Data According to the New ASPRS 2014 Standard", a vertical accuracy class of $10 \mathrm{~cm}(X-\mathrm{cm})$, the correspondence absolute accuracy are: $19.6 \mathrm{~cm}$ in Non-vegetated Vertical Accuracy (NVA) at 95\% Confidence Level and $29.4 \mathrm{~cm}$ in Vegetated Vertical Accuracy (VVA) at $95^{\text {th }}$ Percentile.

Other accuracy parameters can be obtained from the datasheet of the manufacturer of the ALS system. For example, for ALS50 II sensor, after suitable post-processing data, the lateral placement accuracy is 7-64 $\mathrm{cm}$ and vertical placement accuracy is $8-24 \mathrm{~cm}$ (one standard deviation). These values are valid in acquisition condition of full-fieldfilling targets of 10 percent diffuse reflectivity or greater with atmospheric visibility of $23.5 \mathrm{~km}$ or better for flying heights up to $6000 \mathrm{~m}$ AGL (height above ground level) and nominal Field of View of 40 degrees (Leica Geosystems, 2017).

In both geomatics techniques taken in consideration, it is necessary to consider even the influence of the different interpolation methods for DEM generation. Indeed, as shown in the paper of Ismail et al. (2016) concerning a survey by ALS systems on a vegetation area, IDW (Inverse Distance Weighting) and Spline methods give lowest accuracy to the DEM than to Kriging method. Indeed, by an ALS survey on quite flat area (average point density of 2.2 per $\mathrm{m}^{2}$ ) and adopting a DEM with a geometric resolution of $1 \mathrm{~m}$, the RMSE value archived, depending on the interpolation technique, varies between $0.78-1.06 \mathrm{~m}$. In terrain with a slope greater than $15^{\circ}$, Su et al. (2006) have showed that the error range varies between $1.458-1.788 \mathrm{~m}$.

\section{METHOD AND DATA}

\subsection{Error prediction in the calculation of volume changing}

In the case where it is possible to measure directly the side of the rectangular prism of length $a$, width $b$ and height $h$, the volume $V$ is the product of these three components. The variance associated to the measure of this volume is (Bevington, 1969):

$$
\sigma_{V}^{2}=\sigma_{a}^{2}\left(\frac{\partial V}{\partial a}\right)+\sigma_{b}^{2}\left(\frac{\partial V}{\partial b}\right)+\sigma_{h}^{2}\left(\frac{\partial V}{\partial h}\right)
$$

The previous formula is valid for direct measure. In the case of indirect measure, such as the direct georeferncing in the photogrammetry and ASL method, it is necessary to take in account more factors generated by indirect measure. An efficient approach to the estimation of volume uncertainty has been proposed by Hapke (2005) in monitoring a landslide through the photogrammetric method. In this approach, the total model error is transformed to an uncertainty in volume. In addition, because the estimation error decreases as landslide areas become larger (Tseng et al, 2013), total uncertainty volume $\left(\sigma^{2} V_{t}\right)$ is function of following parameters:

$$
\sigma_{V_{t}}^{2}=f\left(E_{t}, V_{t}, A\right)
$$

Where:

$\sigma^{2} V t \quad$ total uncertainty volume;

$E_{t} \quad$ total error (3D) of the model;

$A$ area over which the volume is calculated;

$V_{t} \quad$ volume.

The $E_{t}$ is sum of the error component, which is related to remote sensing technique. Indeed, the total error for photogrammetry purpose, can be write as function of several aspects: error in direct georeferencing, aerial triangulation, determination of Ground Control Points, flying height and image distortions. As concerning the ALS survey, the error is related to: positioning of the carrying platform, orientation determination, offsets between the laser sensor, position and orientation (POS/INS) system and an aircraft platform, errors in the electro-optical parts of the laser sensor, wrong laser and POS/INS data processing, careless integration and interpolation of the INS and GNSS data (Pre-processing), erroneous data from the reference ground GNSS base stations and wrong data/coordinate transformation.

In addition, in order to obtain an estimate of the error as close to reality, the $E_{t}$ value should be taken in account the presence of the vegetation on the AOI. In other words, on the $\mathrm{AOI}$, it is possible to separate the vegetation area (VA) and not vegetation area (eroded or accumulated). In this way, if a different and greater error is not considered in areas covered by high vegetation, than the estimate of the volumes could be too optimistic. Therefore, the formula (1) is the sum of two components, as shown below:

$\sigma_{V t}^{2}=\sigma_{V t(\text { novegetationarea })}^{2}+\sigma_{V t(\text { vegetationarea })}^{2}$ 
Monitoring 4D phenomena, i.e. in terms of spatial and temporal dimensions, the variation of the volume over the time can be expressed by the following formula:

$$
\Delta V=V_{t 1}-V_{t 2}
$$

\section{Where}

$\Delta V \quad$ volume variation;

$V_{t l} \quad$ volume to estimate to time $\mathrm{t}_{1}$;

$V_{t 2} \quad$ volume to estimate to time $\mathrm{t}_{2}$.

Considering two DEMs, summing the $i$ pixel values of difference height $(\Delta H)$ for the Ground Sample Distance (GSD), the difference of volumes $(\Delta V)$ is (Etzelmüller et al, 1993):

$$
\Delta V=G S D^{2} \sum(\Delta H)
$$

The total uncertainty volume in $4 \mathrm{D}$ analysis assumes the following equation:

$$
\sigma_{v t}^{2}=\sigma_{v t 1}^{2}+\sigma_{v t 2}^{2}
$$

The procedure that allows to calculate of the total uncertainty related to volume eroded or accumulate can be sketched as showed in the following workflow (figure 1).

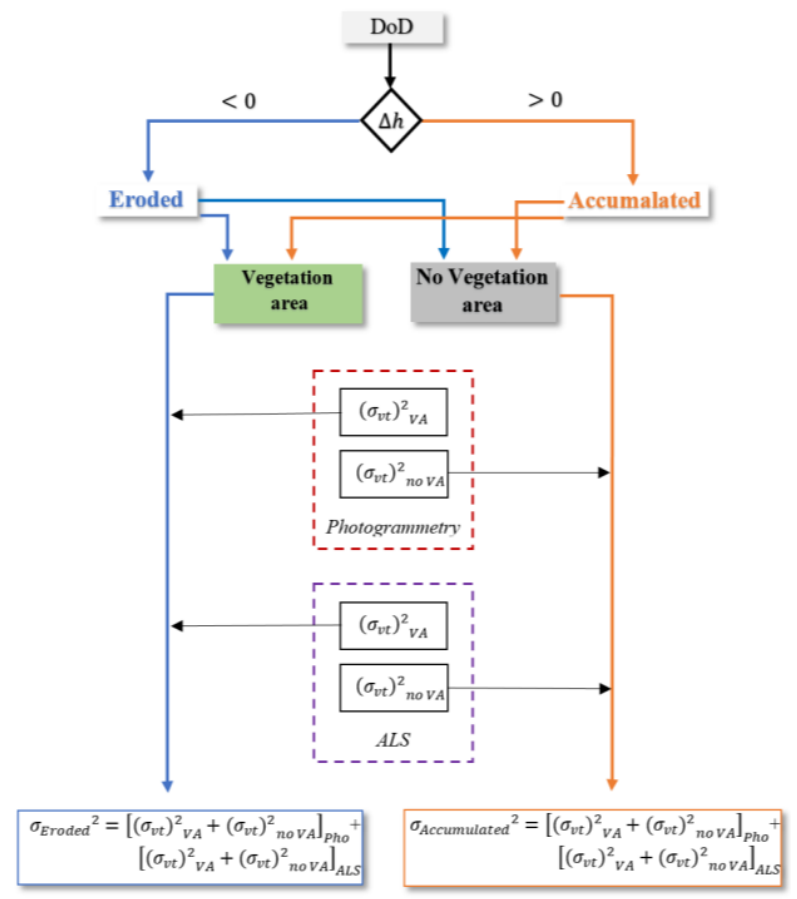

Figure 1. Algorithm to calculate uncertainty volume

\subsection{Study area and datasets}

The area study is located in South Italy, in Campania Region ( $\varphi=41^{\circ} 15^{\prime} 05^{\prime}$ N; $\lambda=15^{\circ} 12^{\prime} 59^{\prime}$ ' E) and concerning an important landslide. Indeed, Montaguto landslide had a length of more than $3 \mathrm{~km}$ and it has distributed over an area of about 45 hectares. This landslide led the closure of an important road link and a railway line for a period of about three months.
In order to estimate the morphology of the terrain after earthflow, two DEM datasets have been considered. The first dataset (before of the landslide) derived by photogrammetric survey while the second (after landslide) by ALS survey.

\subsection{Photogrammetry dataset}

The photogrammetric dataset is constituted by numerical cartography at scale 1:5000 obtained by stereoscopy approach on digital images. The images were acquired by digital photogrammetric camera Z/I DMC (Zeitler et al., 2002; Pepe, 2017a). The most important features of this sensor are: sensor size $13824 \times 7680$ pixels, pixel size $12 \mu \mathrm{m}$, focal length $120 \mathrm{~mm}$; the sensor is able to acquire in panchromatic and multispectral mode.

The special accuracy values reported on the cartography are: $0.75 \mathrm{~m}$ in elevation and $1.0 \mathrm{~m}$ in plan.

So, in order to build the DEM, the vector information contained in the cartography (contour lines, elevation points, etc.) have been transformed in TIN and, subsequently, this latter model has been transformed in raster. These operations have been carried out in ArcGis environment. The first task, i.e. the transformation from vector information to TIN, has been realized by the tool called "Create TIN" surface. In order to do not consider the triangles outside the AOI, the tool called "Delineate Tin Data Area" has been used. This tool modifies the input TIN by reclassifying its edges to be either included or excluded from the interpolation zone. Subsequently, using the tool called "TIN to Raster" it has been possible to interpolate cell z-values from the input TIN at the $0.5 \mathrm{~m}$ resolution. The interpolation method used to create the raster has been "linear". In this way, the tool calculates cell values by applying linear interpolation to the TIN triangles.

\subsection{Lidar dataset}

The survey after earthflow has been realized by ALS sensor in order to obtain a minimum point density on the terrain of $3 \mathrm{pt} / \mathrm{m}^{2}$. The flight planning has been designed and realized by 6 Flight Lines (FLs), which two along the axis of the landslides and other 4 parallel to the central ones.

The ALS survey has been realized at a relative height of 500m using Partenavia P68 aircraft. Because the point density is a function of the acquiring speed (Pepe, 2017b), during the flight it has been paid much attention to respect the velocity of the project. In this way, it has been possible preserve the designed point density. Once completed the flight planning, to obtain the point clouds in a specific mapping frame, it is necessary assembly the three datasets: calibration data and mounting parameters, laser distance measurements with their respective scanning angles and Position and Orientation System data (Wehr \& Lohr, 1999).

The calibration has been performed using a combination of standard and in-house software and factory boresight calibration is set using Leica Geosystems Attune software. The post-processing of the Lidar data has been obtained using several software: Waypoint GrafNav for Differential Global Positioning System (DGPS) processing, Leica Geosystems IPAS Pro in order to manage the combination of GNSS/IMU (Roth \& Thompson, 2008). The GNSS station used for DGPS is the permanent station called "Accadia" belong the Puglia Region GNSS network. The distance between the operations area of survey and master station has been of about $20 \mathrm{~km}$. The trajectory carried out by the aircraft during the acquisition operation is shown in Figure 2. 


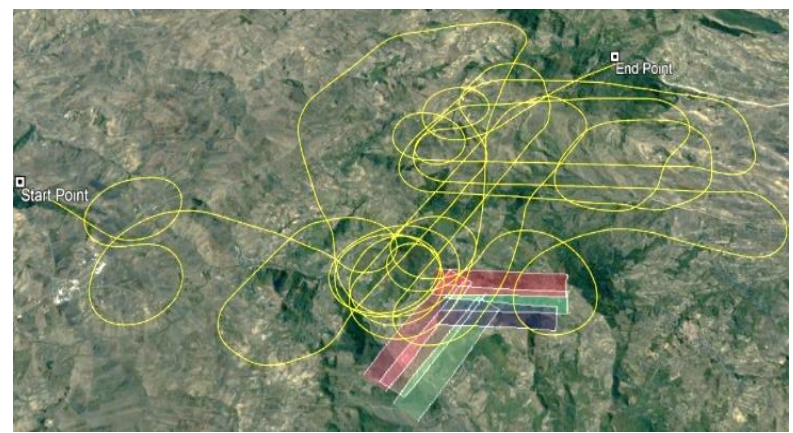

Figure 2. Trajectory on othophoto (Google Earth)

As shown in the figure 2, before and after the execution of the flight lines, the aircraft has carried out an "eight" in flight. This action allows to improve performance of the inertial sensor and thus to avoid the effects of drift over time. Subsequently, using Leica Geosystems ALS Post Processor software, has been generated the point clouds in ASPRS LASer (LAS) File Format (Samberg, 2007; Pepe et al, 2017a; Pepe et al, 2017b). Because the point clouds have been generated in geographic coordinates, in order to simplify the geomatics operations with the point clouds, the projection in a coordinate plane system has been performed.

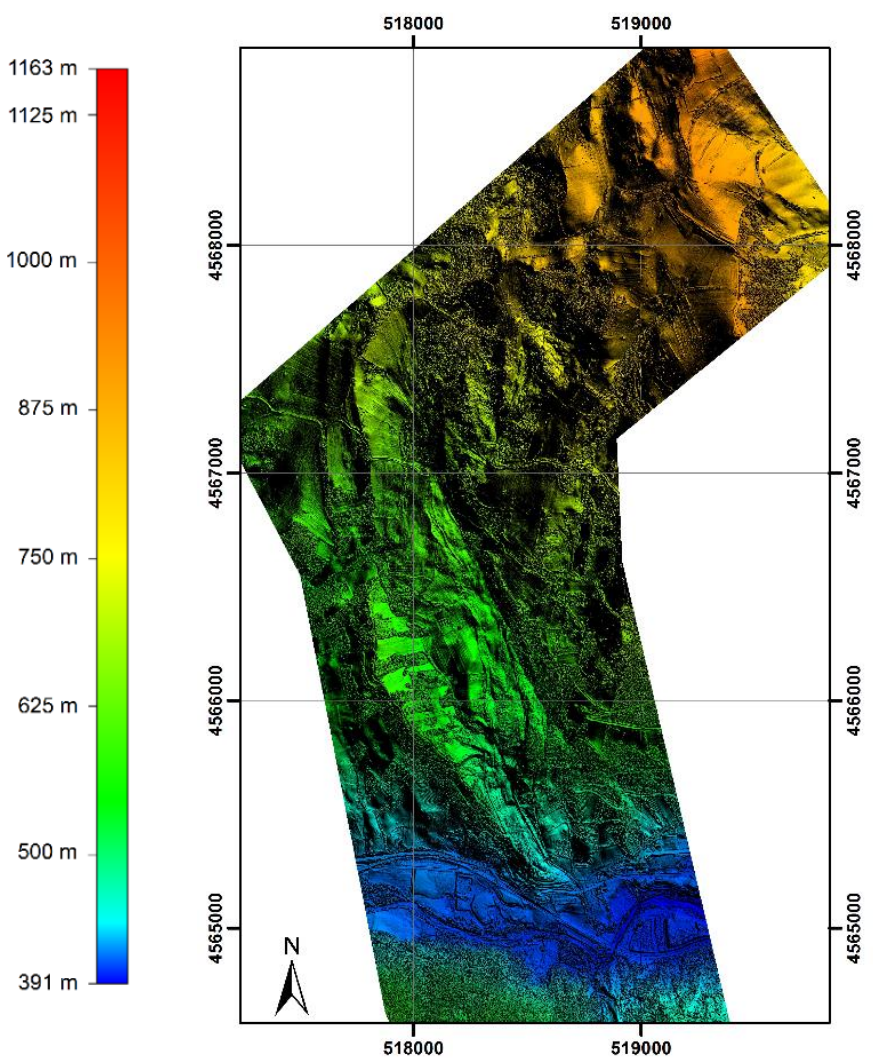

(a)
In particular, because the Italian government has adopted the reference system called ETRF2000 (2008.0) the coordinates of the survey have been represented in RDN2008/TM33. The elevation coordinates produced by direct georeferencing have been generated in the ellipsoidal height $(\mathrm{h})$. In order to obtain the orhometric height $(\mathrm{H})$, it has been necessary to convert this height. Indeed, knowing the geoid undulation model $(\mathrm{N})$ and using a suitable tool developed in Matlab environment, the orthometric point clouds have been obtained. The geoid undulation adopted for the transformation has been Italgeo05 (Barzaghi et al., 2005) because it is the most accurate geoid model available on Italian territory. Subsequently, using specific software of classification, all point clouds have been classified in the following classes (table 1)

\begin{tabular}{|c|c|}
\hline Code & Description \\
\hline 0 & Created, never classified \\
1 & Unclassified \\
2 & Ground \\
3 & Low Vegetation \\
4 & Medium Vegetation \\
5 & High Vegetation \\
6 & Building \\
7 & Low Point (noise) \\
9 & Water \\
\hline
\end{tabular}

Table 1. Classification according *.LAS format



(b)

Figure 3. Digital elevation models in ETRF2000 UTM33 projection. a) DSM; b) DTM. 
The interpolation of the dense sparse point clouds has been realized by Kriging because it is one of the more flexible and accurate gridding methods. This task has been performed using Surfer Golden software.
A representation of the DEMs generated by lidar data within the area of interest, with a geometric resolution of $0.5 \times 0.5$ $\mathrm{m}$, is shown in the figure 3. In particular, the figure 3.a) shows the DSM while the figure 3.b) the DTM generated after data filtering.

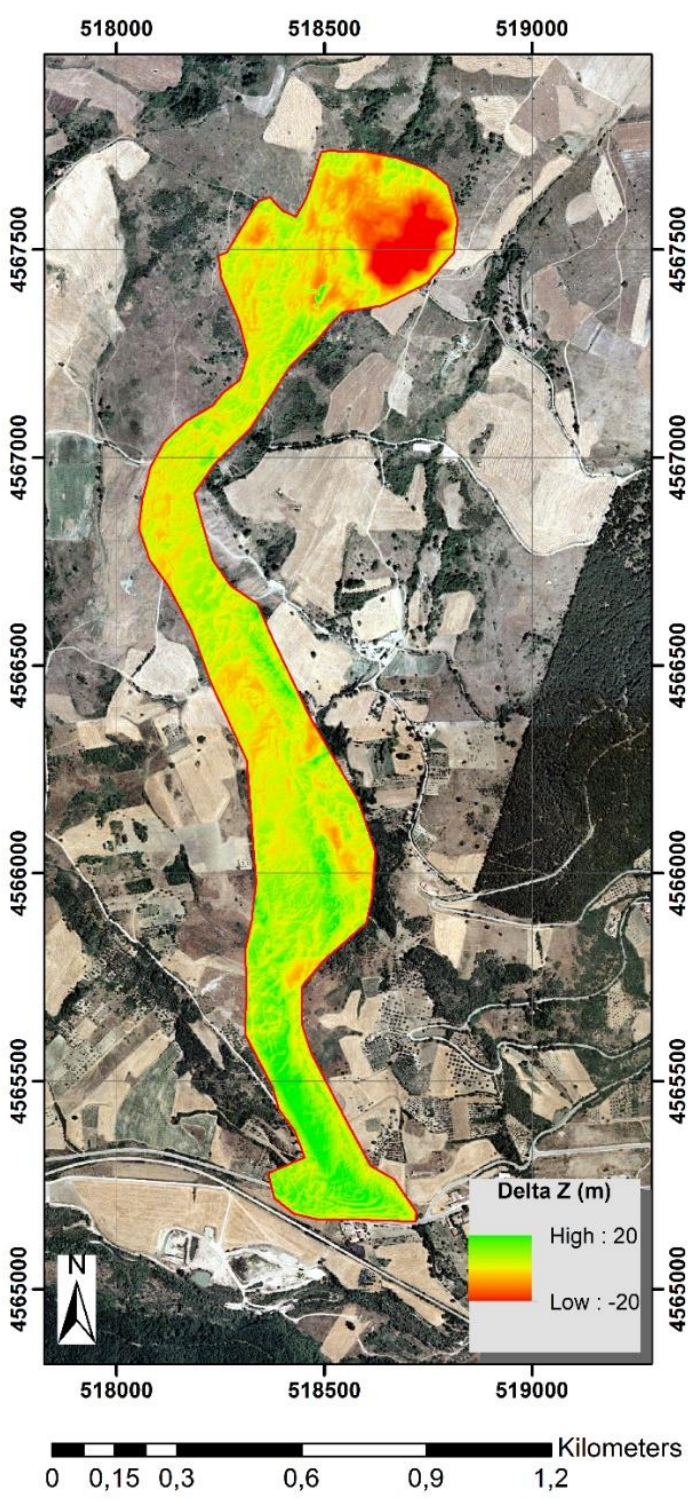

(a)
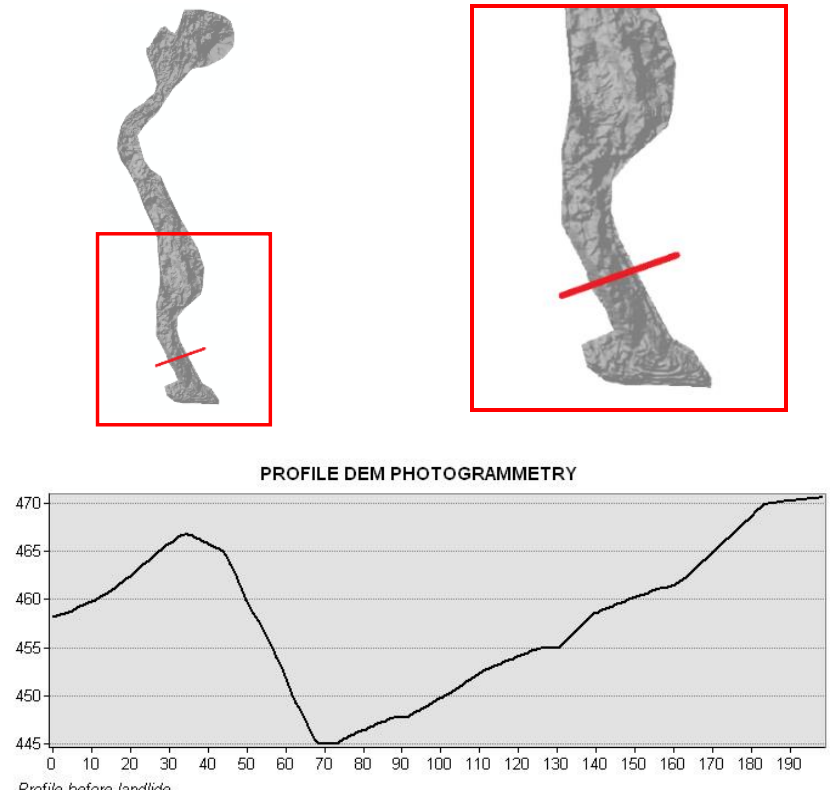

PROFILE DEM ALS
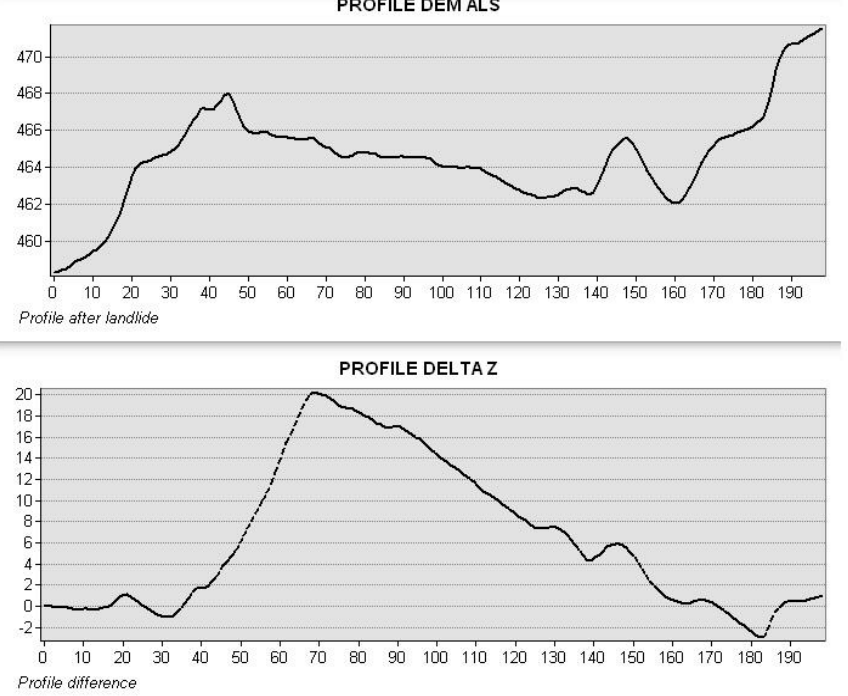

(b)

Figure 4. Analysis of the elevation terrain before and after landslide.

a) DEM of Difference (DoD) on orthophoto.

b) Terrain profile in different times. At the top right is showed the planimetric area with the identification of the section. In this section were extracted the terrain profiles before (photogrammetry data) and after landslide (ALS data). At the bottom of the figure $4 \mathrm{~b}$, is shown the terrain profile extracted from DoD map in the accumulation area. 


\subsection{Analyses of the volume changing: DEM Comparison}

The DEM comparison between the two raster (referring to two different temporal moments) has been conducted using ArcGIS software. Using the tool Raster Calculator, the difference in elevation between the two DEMs has been calculated by following formula:

$$
\text { delta } H=D E M_{A L S}-D E M_{\text {photogrammetry }}
$$

The elevation difference (delta $H$ ) concerning the landslide area is show in the figure $4 \mathrm{a}$.

The boundary of the landslide area has been determined by the use of orthophoto after the landslide. In this way, it has been possible to draw the boundary (polygon feature) in GIS environment.

Based on the morphological characteristics, the Montaguto landslide can be divided into three main sector (Ferrigno et al., 2017): the upper sector represents the source area, the middle sector is the propagation area and the lower sector is the accumulation area (landslide toe).

In each section, the eroded and accumulated volumes have been calculated. A widespread method to evaluate the terrain evolution is the construction of the profile. An example of the profile (transversal to the earthflow direction) before and after landslide in the accumulation area, is shown in figure $4 \mathrm{~b}$ where it is easy to note as the difference in elevation reach values of 20 meters. This last parameter indicates the importance of the landslide that involved this area.

The change of terrain volumes, accumulation and erosion, are respectively $349991 \mathrm{~m}^{3}$ and $869920 \mathrm{~m}^{3}$. Therefore, the total volume balance archived was about $5.2 \cdot 10^{5} \mathrm{~m}^{3}$.

The uncertainty of the volume has been calculated by relation [2], suitably adapted to raster information. The high vegetation in the AOI covers a surface of about $14 \%$ of the area subject to landslides. The heights of trees were obtained in post-processing task, i.e. after obtained the classification of point clouds in several classes. In this way, it has been possible measure the heights of the trees in several zones within the landslide area (figure 5).

Lastly, a terrestrial survey, using Hi-Target V8 GNSS RTK (Real Time Kinematic) system and total station (Pentax NX325 ) has been carried out in order to obtain check points. In this way, it has been possible to compare the spatial coordinates of the check points with the points belongs to ALS and photogrammetry models.

Therefore, the different total errors achievable in relation to vegetation area by photogrammetry and ALS technique are shown in table 2 .

\begin{tabular}{|l|c|c|}
\hline & $E t_{\text {(photogrammetry) }}$ & $E t_{(A L S)}$ \\
\cline { 2 - 3 } & $\mathrm{m}$ & $\mathrm{m}$ \\
Vegetation area & 1.600 & 0.300 \\
No vegetation area & 1.050 & 0.125 \\
\hline
\end{tabular}

Table 2. Total errors of the model occurred in area with and without high vegetation

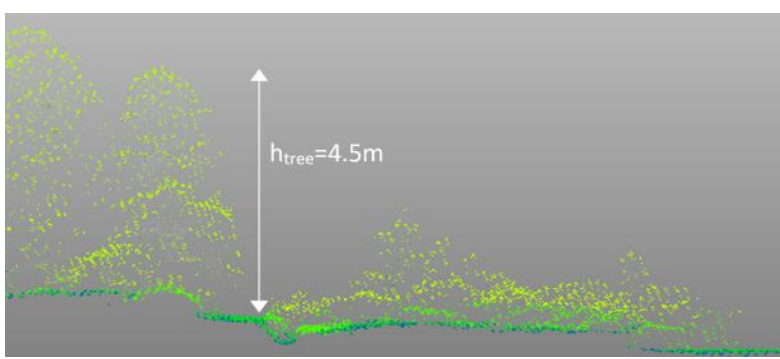

Figure 5. Terrain profile.

Lastly, the terrain volumes values and their relative uncertainties in the area interested by landslide activity are:

- Accumulation: $+349991 \pm 30760 \mathrm{~m}^{3}$;

- $\quad$ Erosion: $-869920 \pm 64720 \mathrm{~m}^{3}$.

\section{CONCLUSIONS}

Due to the numerous parameters that contribute to determining the uncertainty of the volume estimation, the approach in budget error in order to determinate the terrain volume changing after earthflow is almost complex, as shown in the presented case study.

The choice of a specific survey technique can significantly affect the accuracy of the volume estimation. Indeed, especially in dense vegetation areas the photogrammetric survey cannot permit the exact determination of the terrain coordinates (ground level) and of consequence, in the estimate of the volume.

Therefore, in the analysis of landslides, especially in densely vegetated areas, the ALS technology makes an important contribution to the measurement of the terrain. In other words, because it allows to achieve great accuracy, the ALS sensor is a suitable survey technology in order to monitor landslide area, especially if the area under investigation is densely vegetated.

\section{ACKNOWLEDGEMENTS}

This research was part of the "Development of synthetic optical sensors to support data fusion techniques applied to remote sensing images from aircraft, satellite and UAV", a research project supported by Campania Region (PO FSE CAMPANIA 2014-2020 - ASSE III) and the University of Naples "Parthenope".

In addition, the authors thanks Avioriprese srl, aerial survey company, for providing the raw lidar data.

\section{REFERENCES}

ASPRS, 2014. Accuracy Standards for Digital Geospatial Data, Photogrammetric Engineering \& Remote Sensing, Vol. 81 , No. 3, p. 53.

Barzaghi, R., Borghi, A., Carrion, D., Sona G., 2007. Refining the estimate of the Italian quasi-geoid. Bollettino di Geodesia e Scienze Affini, $\mathrm{n}^{\circ} 3$. 
Bevington, P.R. 1969, Data Reduction and Error Analysis for the Physical Sciences. New York: McGraw-Hill, Chapter 2.

Bitelli, G., Dubbini, M., \& Zanutta, A., 2004. Terrestrial laser scanning and digital photogrammetry techniques to monitor landslide bodies. International Archives of Photogrammetry, Remote Sensing and Spatial Information Sciences, 35(B5), pp. 246-251.

Bossi, G., Cavalli, M., Crema, S., Frigerio, S., Quan Luna, B., Mantovani, M., ... \& Pasuto, A., 2015. Multi-temporal LiDAR-DTMs as a tool for modelling a complex landslide: a case study in the Rotolon catchment (eastern Italian Alps). Natural Hazards and Earth System Sciences, 15(4), pp. 715-722.

Brückl, E., Brunner, F. K., \& Kraus, K., 2006. Kinematics of a deep-seated landslide derived from photogrammetric, GPS and geophysical data. Engineering Geology, 88(3), pp. 149159 .

Colesanti, C., \& Wasowski, J. (2006). Investigating landslides with space-borne Synthetic Aperture Radar (SAR) interferometry. Engineering geology, 88(3), pp. 173-199.

Csanyi, N., Toth, C.K., 2007. Improvement of Lidar Data Accuracy Using Lidar-Specific Ground Targets. Photogrammetric Engineering \& Remote Sensing, 73 (4), pp. 385- 396.

Etzelmüller, B., Vatne, G., Ødegârd, R. S., \& Sollid, J. L., 1993. Mass balance and changes of surface slope, crevasse and flow pattern of Erikbreen, northern Spitsbergen: an application of a geographical information system (GIS). Polar Research, 12(2), pp. 131-146.

Farrance, I., \& Frenkel, R., 2012. Uncertainty of measurement: a review of the rules for calculating uncertainty components through functional relationships. The Clinical Biochemist Reviews, 33(2), 49.

Ferrigno, F., Gigli, G., Fanti, R., Intrieri, E., \& Casagli, N., 2017. GB-InSAR monitoring and observational method for landslide emergency management: the Montaguto earthflow (AV, Italy). Natural Hazards and Earth System Sciences, 17(6), 845.

Fookes, P. G., Dale, S. G., \& Land, J. M., 1991. Some observations on a comparative aerial photography interpretation of a landslipped area. Quarterly Journal of Engineering Geology and Hydrogeology, 24(3), pp. 249-265.

Garnero, G., \& Godone, D., 2013. Comparisons between different interpolation techniques. Proceedings of the international archives of the photogrammetry, remote sensing and spatial information sciences XL-5 W, 3, pp. 2728.

Goudie, A. S., 2006. The Schmidt Hammer in geomorphological research. Progress in Physical Geography, 30(6), pp. 703-718.

Hapke, C. J., 2005. Estimation of regional material yield from coastal landslides based on historical digital terrain modelling. Earth Surface Processes and Landforms, 30(6), pp. 679-697.
Hopkinson, C., Chasmer, L. E., Sass, G., Creed, I. F., Sitar, M., Kalbfleisch, W., \& Treitz, P., 2005. Vegetation class dependent errors in lidar ground elevation and canopy height estimates in a boreal wetland environment. Canadian Journal of Remote Sensing, 31(2), pp. 191-206.

Ismail, Z., Abdul Khanan, M. F., Omar, F. Z., Abdul Rahman, M. Z., \& Mohd Salleh, M. R., 2016. EVALUATING ERROR OF LIDAR DERIVED DEM INTERPOLATION FOR VEGETATION AREA. International Archives of the Photogrammetry, Remote Sensing \& Spatial Information Sciences, 42. pp.141150.

Jaboyedoff, M., Oppikofer, T., Abellán, A., Derron, M. H., Loye, A., Metzger, R., \& Pedrazzini, A., 2012. Use of LIDAR in landslide investigations: a review. Natural hazards, 61(1), pp. 5-28.

James, L. A., Hodgson, M. E., Ghoshal, S., \& Latiolais, M. M., 2012. Geomorphic change detection using historic maps and DEM differencing: The temporal dimension of geospatial analysis. Geomorphology, 137(1), pp. 181-198.

Karsli, F., Yalcin, A., Atasoy, M., Demir, O., Reis, S., \& Ayhan, E., 2004. Landslide assessment by using digital photogrammetric techniques. In Proceedings 20th ISPRS Congress, Commission VII, Turkey, pp. 736-739.

Kraus, K., and Pfeifer, N. 1998. Determination of terrain models in wooded areas with airborne laser scanner data. ISPRS Journal of Photogrammetry and Remote Sensing, Vol. 53, pp. 193-203.

Lee, S., \& Min, K., 2001. Statistical analysis of landslide susceptibility at Yongin, Korea. Environmental geology, 40(9), pp. 1095-1113.

Leica Geosystems, 2017. Airborne Laser Scanner Product Specifications. Last accessed: 13/10/2017.

http://www.nts-info.com/inventory/images/ALS50-

II.Ref.703.pdf

Leitold, V., Keller, M., Morton, D. C., Cook, B. D., \& Shimabukuro, Y. E., 2015. Airborne lidar-based estimates of tropical forest structure in complex terrain: opportunities and trade-offs for REDD+. Carbon balance and management, 10(1), 3 .

Maglione, P., Parente, C., Santamaria, R., \& Vallario, A., 2014. Modelli tematici 3D della copertura del suolo a partire da DTM e immagini telerilevate ad alta risoluzione WorldView-2. Rendiconti Online della Società Geologica Italiana, 30, pp. 33-40.

Nichol, J. E., Shaker, A., \& Wong, M. S., 2006. Application of high-resolution stereo satellite images to detailed landslide hazard assessment. Geomorphology, 76(1), pp. 68-75.

Osmanoğlu, B., Sunar, F., Wdowinski, S., \& Cabral-Cano, E., 2016. Time series analysis of InSAR data: Methods and trends. ISPRS Journal of Photogrammetry and Remote Sensing, 115, pp. 90-102. 
Passini, R., \& Jacobsen, K., 2008. Accuracy analysis of large size digital aerial cameras. International Archives of Photogrammetry, Remote Sensing and Spatial Information Sciences, 37(B1), pp. 507-51.

Pepe, M, 2017a, Use of Digital Aerial Photogrammetry Sensors for Land Cover Classification, International Journal of Applied Engineering Research, 12(24), pp. 15610-15620.

Pepe, M., 2017b, A survey by Airborne Laser Scanner of open large structure: A case study of Pompeii Amphitheatre, ARPN Journal of Engineering and Applied Sciences, 12(21), pp. 1-11.

Pepe, M., Ackermann, S., Fregonese, L., \& Achille, C., 2017a. New Perspectives of Point Clouds Color Management-the Development of Tool in Matlab for Applications in Cultural Heritage. ISPRS-International Archives of the Photogrammetry, Remote Sensing and Spatial Information Sciences, pp. 567-571.

Pepe, M., Parente, C., 2017b, Cultural Heritage Documentation in SIS Environment: an application for "Porta Sirena" in the archaeological site of Paestum. In International Archives of the Photogrammetry, Remote Sensing \& Spatial Information Sciences, 42, pp. 427-432.

Razak, K. A., Straatsma, M. W., Van Westen, C. J., Malet, J. P., \& De Jong, S. M., 2011. Airborne laser scanning of forested landslides characterization: Terrain model quality and visualization. Geomorphology, 126(1), pp.186-200.

Reutebuch, S. E., McGaughey, R. J., Andersen, H. E., \& Carson, W. W., 2003. Accuracy of a high-resolution lidar terrain model under a conifer forest canopy. Canadian journal of remote sensing, 29(5), pp.527-535.

Roth, R. B., \& Thompson, J., 2008. Practical application of multiple pulse in air (MPIA) Lidar in large-area surveys. Proceedings of international archives of the photogrammetry, remote sensing and spatial information sciences, pp.183-188.

Samberg, A., 2007. An implementation of the ASPRS LAS standard. In International Archives of the Photogrammetry, Remote Sensing and Spatial Information Sciences Workshop on Laser Scanning and SilviLaser, pp. 363-372.

Seker, D. Z., Altan, M. O., Duran, Z., Shrestha, M. B., Yuasa, A., \& Kawamura, K., 2004. Producing landslide risk map of Sebinkarahisar by means of remote sensing and GIS techniques. In Proceedings of ISPRS XXth Congress, Istanbul, Turkey, Vol. 35, pp. 465-469.

Su, J., \& Bork, E., 2006. Influence of vegetation, slope, and lidar sampling angle on DEM accuracy. Photogrammetric Engineering \& Remote Sensing, 72(11), pp.1265-1274.

Tseng, C. M., Lin, C. W., Stark, C. P., Liu, J. K., Fei, L. Y., \& Hsieh, Y. C., 2013. Application of a multi-temporal, LiDAR-derived, digital terrain model in a landslide-volume estimation. Earth Surface Processes and Landforms, 38(13), pp. 1587-1601.

Vosselman, G., 2008. Analysis of planimetric accuracy of airborne laser scanning surveys. International Archives of
Photogrammetry, Remote Sensing and Spatial Information Sciences, 37, pp. 99-104.

Vosselman, G., Maas, H.-G., 2001. Adjustment and filtering of raw laser altimetry data. In: Proceedings of OEEPE Workshop on Airborne Laserscanning and Interferometric SAR for Detailed Digital Terrain Models, Stockholm, Sweden.

Wehr, A., \& Lohr, U., 1999. Airborne laser scanning - an introduction and overview. ISPRS Journal of photogrammetry and remote sensing, 54(2), pp. 68-82.

Williams, R., 2012. DEMs of difference. Geomorphological Techniques, 2(3.2).

Zeitler, W., Doerstel, C., \& Jacobsen, K., 2002. Geometric calibration of the DMC: Method and Results. International Archives of Photogrammetry Remote Sensing and Spatial Information Sciences, 34(1), pp. 324-332. 